\title{
Vaccination uptake and health service access amongst Polish and Romanian communities in England: a qualitative interview study - research summary
}

\author{
Sadie Bell, Mateusz Zatoński, Sandra Mounier-Jack \\ Faculty of Public Health and Policy, London School of Hygiene \& Tropical Medicine, London, UK
}

\begin{abstract}
At the London School of Hygiene and Tropical Medicine, we are conducting a study to explore vaccination uptake and health service access amongst Polish and Romanian communities in England. In this summary, we provide the rationale for conducting this research and an overview of the study design.
\end{abstract}

KEY WORDS: vaccination, qualitative methods, health service access, UK, Polish migrants, Romanian migrants.

ADDRESS FOR CORRESPONDENCE: Dr. Sadie Bell, London School of Hygiene \& Tropical Medicine, 15-17 Tavistock Place, London, WC1H 9SH, United Kingdom, phone: 0207927 2885, e-mail: sadie.bell@Ishtm.ac.uk

\section{INTRODUCTION}

At the London School of Hygiene and Tropical Medicine, we are conducting a study to explore the health service experiences of Polish and Romanian immigrants in England, with a specific focus on the uptake of recommended vaccinations.

The study has three aims: 1 . Investigate the acceptability and uptake of vaccinations amongst Polish and Romanian communities; 2 . Explore perceptions and the experiences of Polish and Romanian communities in accessing health services; 3 . Identify potential interventions to improve vaccination uptake and health service acceptability amongst Polish and Romanian communities.

\section{WHY IS RESEARCH NEEDED?}

In 2015, Poland and Romania were among the top five most common countries of nationality amongst non-British UK citizens; Poles constituted $15.7 \%$ of non-British UK citizens and Romanians 4.0\% [1]. Despite large Polish and Romanian communities in the UK, there is currently limited research on vaccination uptake and experiences of health services amongst these groups. A barrier to researching these topics is that nationality and country of birth data are largely unre- corded e.g. for general practice registrants, and Poles and Romanians are often included within the broad ethnic category of 'white - other'. Research exploring immunisation uptake by ethnicity, a concept often linked to migrant status [2] has largely included broad ethnic categories, not looking at specific nationalities or countries of birth [3-5].

As vaccination programmes vary between countries, and given the recent vaccine-preventable disease outbreaks across Europe, this is a particularly important research area. The study will produce recommendations to enhance services for Polish and Romanian communities. These will be used to directly inform service improvements.

\section{WHAT METHODS ARE WE USING?}

We are conducting semi-structured interviews with men and women from Poland and Romania (living in the UK since these countries joined the EU in 2004 and 2007 respectively) that are able to discuss vaccinations in relation to their children or themselves (e.g. if they are eligible for the flu vaccine). During the interviews, participants are asked to share their experiences of vaccination and health services in the UK. 
We are also interviewing healthcare professionals involved in vaccination delivery (e.g. general practitioners, practice nurses and health visitors) in areas of England with large Polish and Romanian communities. In these interviews, we are asking participants to share their experiences in delivering health services to these communities, particularly focusing on the vaccination programme.

We plan to interview 30 Polish and Romanian participants and 30 healthcare professionals. Recruitment is targeted to areas of England with high proportions of Polish and Romanian residents. We are recruiting Polish and Romanian participants using social media (e.g. via Facebook and Twitter), through advertisement in shops, Polish and Romanian organisations and local groups, and via other community settings (e.g. churches, nurseries, libraries). Healthcare professionals are being recruited through general practices and other healthcare providers. We are currently recruiting to the study and intend to disseminate the study findings from March 2018.

\section{ACKNOWLEDGEMENT}

The study has been granted ethical approval by the Observational Research Ethics Committee at the London School of Hygiene \& Tropical Medicine, NHS Health Research Authority approval (IRAS project ID: 224734), and site-specific NHS Research and Development department approvals.

The study is funded by the National Institute for Health Research (NIHR) as part of the Health Protection Research Unit (HPRU) in Immunisation.

\section{DISCLOSURE}

Authors report no conflict of interest.

\section{References}

1. Vargas-Silva C, Rienzo C. Migrants in the UK: An Overview. 2017. Available from: http://www.migrationobservatory.ox.ac. $\mathrm{uk} /$ resources/briefings/migrants-in-the-uk-an-overview/ (accessed: 13 November 2017).

2. Bhopal R. Glossary of terms relating to ethnicity and race: for reflection and debate. J Epidemiol Community Health 2004; 58 : 441-445.

3. Baker D, Garrow A, Shiels C. Inequalities in immunisation and breastfeeding in an ethnically diverse urban area: cross sectional study in Manchester, UK. J Epidemiol Community Health 2010; 65: 346-352.

4. Baker MR, Bandaranayake R, Schweiger, MS. Differences in rate of uptake of immunisation among ethnic groups. Br Med J (Clin Res Ed) 1984; 288: 1075-1078.

5. Boyer HL, Forster AS, Marlow LAV, Waller J. Predicting human papillomavirus vaccination behaviour among adolescent girls in England: results from a prospective survey. J Fam Plann Reprod Health Care 2014; 40: 14-22.

\section{AUTHORS' CONTRIBUTIONS}

SB wrote the first full draft of the article. SB, MZ, SMJ prepared the final version of the article.

in this area, both in Poland and in the extensive Polish diaspora.

\section{References}

1. Office for National Statistics. Population of the UK by country of birth and nationality: 2016. ONS Statistical bulletin 2017. Available from: https://www.ons.gov.uk/peoplepopulationandcommunity/populationandmigration/internationalmigration/bulletins/ukpopulationbycountryofbirthandnationality/2016. (accessed: 14 October 2017).

2. Janik-Koncewicz K, Zatoński M, Herbeć A, Zatoński W. The role of the Health Promotion Foundation in building capacity to treat tobacco dependence in Poland: past, present and future. J Health Inequal 2017; 2: 127-132.

3. Gorman DR, Stoker RD. Breast screening uptake in Polish women in Scotland. Divers Equal Health Care 2015; 12: 152-154.

4. Marchewka AK, Majewska A, Młynarczyk G. Działalność ruchu antyszczepionkowego, rola środków masowego komunikowania oraz wpływ poglądów religijnych na postawę wobec szczepień ochronnych [The activity of antivaccine movement, role of the mass media and influence of religious beliefs on the attitude towards immunization]. Post Mikrobiol 2015; 54: 95-103. 